\title{
ESTABLISHING, STRUCTURE AND SELECTION OF JUDGES IN THE EUROPEAN COURT OF HUMAN RIGHTS
}

\begin{abstract}
Nenad Petrov
master`s student at the Faculty of Law at University "Goce Delchev"-Shtip, North Macedonia, pencoesteban@gmail.com
\end{abstract}

\begin{abstract}
Main purpose of this paper is to review the development and organizational structure of the European Court of Human Rights in Strasbourg, primarily the idea ofestablishing such body is to ensure the protection of the rights guaranteed in the Convention of Human Rights and the same are being violated by countries petitioners, the problems which have arisen in its functioning, the reforms which have been carried out in order to resolve such problems, until its present form. In addition, we will pay attention to its organizational structure selection and structure of the court.
\end{abstract}

Key words: Establishment of the court, Selection and structure of the court, $A D$ HOC and judges in case of common interest, Ineligibility to perform the function and withdrawal.

\section{Introduction}

The idea that all people have rights that no one has the right to abolish them is an old opinion. In the sacred writings this is expressed by pointing out that human is created according God's personality, so humans are inviolable. No man has the right to take away what God has given him. Human rights are those rights that all humans were born with, they are universal. This means that everyone has these rights no matter where on the globe they live. Human rights should not be bought, earned or inherited - they are called "inalienable" because no one has the right to seize them from anyone for any reason. This means that they are inherent for every human
Professional Paper doi:10.5937/jouproman8-23971 being, regardless the race, skin color, gender, language, religion, political or other opinion, national or social origin, property, birth status or other status. Human rights are especially important in relations between people and the country. They control and regulate the exercise of state government over individuals, grant individuals freedom in respect to the state, and require the state to meet the basic needs of the people under its jurisdiction. These rights are best described in the international texts (or instruments) agreed upon the countries which set the human rights standards. One such document is the European Convention of Human Rights which protects fundamental human rights, expressed through protocols that have a strong influence in almost the entire legal and political world. As a result of one of these protocols (Protocol 11 to the European Convention of Human Rights), the European Court of Human Rights has become the only institution in protection of the human rights established in the Convention. Placing this kind of institution in such a high level is essential for continuous control, as well as a kind of arbitration against any form or attempt for violation of a particular human right contained in the Convention. 
Considering that the judgments of the European Court are final and effective, and they are binding and enforceable for the countries members of the Council of Europe, the conclusion is that the European Court of Human Rights has a role very similar to the one of the Constitutional Courts in the national legal systems.

\section{Establishing of new court}

The European Court of Human Rights is a unique body in the history of international law. More than 800 million people have direct access and an opportunity to lodge complaints for violations of their fundamental rights. The court is at the very heart of the human rights protection system, which influences the democratic legal order of almost all European countries. It establishes standards that overflow into the legal regimes of the contractual countries and has a huge contribution in modeling of domestic legislation and practice in almost every area of the law, such as administration of criminal justice, civil and criminal law, family and property law, etc. This is a remarkable achievement for the international tribunal, which was established in 1959 in order to provide an early warning system against weakening democratic standards or possible occurrence of dictatorships. This essential political mandate was supposed to be achieved through functioning the law, and in particular through the right of submission of an individual complaint.

The current existing Court, which began working on $1^{\text {st }}$ of November 1998 with the entry of Protocol 11, is a product of the fusion of two separate, temporary bodies which are not functioning at the moment - the European Commission of
Human Rights and the Former Human Rights Court $^{1}$. The appeals were first lodged to the Commission; they were referred to the Committee of ministers and, depending the circumstances, submitted by one of the two bodies to the court for a decision. Then, the individuals could not file their lawsuits directly to the court. The adoption of Protocol 11 was initiated by a series of factors: the growing burden on the Commission and the Court was replaced by a single permanent institution, composed of one judge of each country -party of the Convention. Judges are permanently placed in Strasbourg and cannot be engaged in any activity incompatible with the requirement of the function with a full working time. Protocol 11 also abolished the formal requirement that the contracting countries should recognize the jurisdiction of the Court before proceeding with a specific case. The "revolutionary" of the protocol consisted in introduction of a new permanent Court (located in Strasbourg), which replaced the entire machinery, in order to make it more accessible to individuals, to speed the court procedure and to achieve greater efficiency in that context. $^{2}$
${ }^{1}$ For the functioning of the former Commission and Human rights court see chapter 22 and 24 of the law on European convention for human rights from Harris, O Boil and Varbrik.

${ }^{2}$ Consequently to this, the old Court stopped functioning on 31 of October 1998, and by the Protocol was established the Commission to continue its work (another calendar year, or until 31 of October 1999) in respect to those cases whose "admissibility" was established prior to the entry of the Protocol. During the "one year preparatory period", without undertaken all relevant organizational and procedural measures, including the preparation of the new Rulebook of the European court of Human rights 
Beside this, the role of the Committee of ministers has been reduced to monitoring the execution of the Court's verdicts and can no longer decide about the validity of cases not referred to the Court. Accordingly, the Court's current role goes beyond judgment only on material issues raised in one case. This is a versatile Court, which inherits from the Commission the essential tasks of filtration of appeals, establishing facts, assessing admissibility and negotiating amicable solutions, in addition to adopting compulsory and binding decisions in the allowed cases.

Permanent growth in the number of cases before the Court since 1998 requires constant change of the working methods in order to find ways of excluding apparently forbidden cases through one economic procedure. ${ }^{3}$ But it soon became clear that Protocol 11 was insufficient and that additional structural changes (reform of the reform) were needed to enable the Court effective functioning. This led to creation of Protocol 14, which was ratified by 46 countries except $1-$ Russia $^{4}$. It is also recognized the permanent rise in cases of $12 \%$ per year. The Court has gradually led to suppression of the Court and demolition of its authority. In 2005, the Committee of ministers set up a Group of wise men to research the future of the Court and establish a model for its long-term development.

The group came up with a Report in November 2006 offering a number of farreaching proposals. However, it was clear that the opinion of the Group was based on

${ }^{3}$ In January 2008 there were 79400 cases pending before the Court waiting to be decided and totally 103850 appeals. So, in pre-trial phase there were 24450 . Only 5 countries granted base for $58 \%$ of all appeals; Russia $(23,6 \%)$, Romania $(11,7 \%)$, Turkey $(9,8 \%)$ and Poland $(5,3 \%)$.

${ }^{4}$ page 863-7 law on European convention for human rights from Harris, O Boil and Varbrik. the assumption that changes from Protocol 14 shall be established soon and that future discussion of their proposals will be enriched with their information on how the changes made with this Protocol work. So the reform process actually stopped, but only temporarily, as Russia's final decision on ratification of the Protocol was awaited.

It happened on 18 of February 2010, which allowed its effective implementation since 1 of June 2010. This Protocol allows one single judge, instead of a Committee of three judges, to declare a complaint as unacceptable and to delete it from the Register. This way shall be decided in simpler subjects. The committee of three judges shall again be able to adopt verdicts in cases where seven judges were required so far. The European Court of Strasbourg by the Protocol 14 is authorized to reject appeals under certain terms, i.e. when the applicants "have not suffered any greater damage". According to statistics, over 90 percent of cases in Strasbourg are rejected as groundless.

\section{Structure of the court}

Section II of the Convention regulates the functioning of the Court and its procedures. Article 30 stipulates that the number of judges shall be as the number of contractual countries: hence, there are currently 47 judges. ${ }^{5}$ They are selected for a period of 6 years, with a right to be reselected again, although under Protocol 14, after the transitional period, it is envisaged introduction of a one-year nonrenewable mandate in duration of 9 years, in order straightening the judicial uncertainty.

${ }^{5}$ For the details of the current structure of the court see internet site of the Court- http://www.echr.coe.int 
The mandate of the judges expires when they reached the age of 70 and the contractual country shall be required not to nominate a person who will not be able to serve the full mandate of 6 years, because of this rule. However, when this is read in the light of the provision of article 23 paragraph 7 (judges remain on function until their replacement) it inserts certain confusion. In practice, judges in the age 70 continue to perform their function until they are replaced. Questions can also be raised about whether it is desirable to have a single judicial body major as this, and the Report of the Wise man presented to the Committee of ministers in November 2006 suggested a reduction in the number of judges, although this would be an amendment of article 20, and any reformed system shall require assurance of the countries - contractual to agree on some objective arrangement for nomination of less judges than there are country parties. ${ }^{6}$

The criteria for performing the function are defined in article 21 of the Convention, which specifies that judges should have "the highest moral reputation" and must possess classifications required for performing high judicial functions or to be legal experts with recognized competence. The latter term, what is considered to be "experts in the law" significantly, expands the field for finding suitable candidates. The result is a Strasbourg judiciary with various professional backgrounds: the Court currently includes former judges of supreme and constitutional courts,

\footnotetext{
6 This will always be a matter of argument as countries are committed to the principle of "one country, one judge." There is no requirement that a judge should be a citizen of the country from which he is nominated (for example, Judge McDonald, a Canadian citizen, is sitting on behalf of Liechtenstein 1980-98), although the Court has emphasized the value of a national judge by knowledge of the national law and procedures, see the Advisory Opinion of 12 February 2008, below in this paper 4
}

researchers, former diplomats, prosecutors and practitioners from the law chambers of the contractual countries.

According the nature of each permanent court, article 21 paragraph 3 requires that judges are not engage in activities which are incompatible with their independence and impartiality or with the requirements for full working time. Article 4 of the Rules of Court supplements this by stating that they shall not be involved in any political or administrative activity which is not compatible with their independence or impartiality. Judges are expected to work full-time in Strasbourg. All of the new judges are informed about this by the President of the Court and this additionally strengthened by their oaths given when entering the function and by the electoral procedures of the Parliamentary Assembly of the Council of Europe (PACE). Article 4 provides that judges must also report any additional activity to the President and in case of disagreement between the President and the judge concerned, the Plenary Assembly of the Court shall decide on any issue. There are rare exceptions to this, however, because some judges who are university professors allow the title professor to be retained.

The independency of the judge is intensive by court submissions. These can be aligned with the salaries of the highest paid judges at the highest instances in the country-members of the Council of Europe. Every one or two countries pay their judges to the highest courts more than the European ones. Judge submissions are free from tax and duties, and beside this, judges have functional diplomatic immunity. ${ }^{7}$

\footnotetext{
${ }^{7}$ Unlike a jurist who is employed by the Court, the judge does not have any pension, so if he wants to retire he has to pay contributions by himself.
} 
Article 51 of the Convention authorizes judges with certain privileges and immunities in performing their functions, thereby enhancing the independency of the Court. Today they are regulated by the Sixth protocol of 1996 to the General Agreement on the privileges and immunities of the Council of Europe, ratified by almost all contractual countries. By this the judges have privileges and immunities of diplomats and guarantee them immunity from legal process in respect of words or actions in performance of their duties. It also guarantees the inviolability of their documents and correspondence, as well as the one of the Court and the Register. Article 4 of the Protocol provides that immunity may be taken only by the Plenary Assembly of the Court.

In his work, the President of the Court is assisted by two vice-presidents, who are also presidents of the boards, and three additional presidents of the Boards (or judicial councils), all elected by the Plenary Assembly of the Court for a mandate of three years, which may be renewed once more. ${ }^{8}$ The Convention itself remains silent in respect to many duties now performed by the President, except for the statement that he (or she), together with the vicepresidents and presidents of the judicial councils, will automatically be members of the Great judicial council, and even then, in practice, this duty may be delegated.
The role of the President is discussed in details in article 9 of the Rules of Procedure. ${ }^{9}$ The first paragraph specifies that the president directs the work and management to the Court and represents it externally, especially in relations with the organs of the Council of Europe. He/she is authorized to adopt practical directions (article 32). These are quite broad duties and include regulation of the relation between the Court and its Registry, the establishment and maintenance of links to national courts and governments (including protocol matters, such as receiving delegations in the Court) and relations with the Committee of ministers and the Secretariat of the Council of Europe, including, most important, budgetary issues. Maintaining good relations between the Court and other parts of the Council of Europe can be a difficult task, not only because the President must ensure that the Court remains fully independent in judicial matters, yet recognizing that, at least in administrative aspect, the Court and the Registry are autonomous parts of the wider system of Council of Europe. For the judicial functions of the President, article 9 paragraph 2 clarifies that: he/she presides to the plenary sessions of the Court, sessions of the Great judicial council and the sessions of the panels of 5 judges, that review the requests for delivery of cases to the Great judicial council. In practice, these roles can be delegated to one of the two vice presidents and shall always be delegated to the counterparty from which the president was selected.
${ }^{8}$ Article 26 of the convention. Although this article only stipulates that they can be re-selected again, article 8 paragraph 3 of the Rules of the Court limits this to only one reelection. Article 8 paragraph 5 defines an elaborate procedure for their election.
${ }^{9}$ The role of the bureau is to assist the President in conducting the work and administration of the Court. It consists of the President, two vice-presidents, the presidents of the boards, the secretary and the deputy secretary, of the Secretariat, article 9 of the Rules of Court. 
The Convention does not stipulate resignation of the function judge. This is regulated by the Rules of Court. The resignation is submitted to the President of the Court, who submits it to the general secretary of the Council of Europe. Unlike the resignation, the Convention provides dismissal of the function judge. For the dismissal it is required consent of twothirds of the judges who can adopt their decision that a judge no longer meets the conditions for judicial function. The judge who is going to be dismissed must at first be heard at the General session of the Court. A proposal for dismissing judge may be submitted by any judge.

\section{Selection of the judges}

Article 22 entrusts the selection of judges to the Parliamentary assembly of the Council of Europe, which performs the selection from a list of three candidates nominated by the Contracting Party. The submitted lists are sometimes controversial. Although the selection is a matter of the Parliamentary assembly, it is unclear whether it can impose conditions over the candidates and what are they. Pursuant to its Resolutions 1366 (2004) and 1436 (2005), the practice of the Parliamentary assembly is that it will not vote for a list until is not satisfied that certain conditions are met, such as: all three nominees meet the terms to be judges, demonstrate sufficient independence from the nominating country, be able to work in at least one of the official languages of the Court, be prepared to live in Strasbourg and, in the interest of gender balance, the list must have at least one man or one woman. ${ }^{10}$ The Government of the Country which has ratified the Convention is obliged to nominate three candidates, who must be such that either of them can be selected. The list of three candidates, compiled by the government, is submitted to the Parliamentary assembly of the Council of Europe, and the procedure of nominating and selecting a candidate on a national level must meet all conditions for fair competition.

The Parliamentary Assembly delivers the list of candidates from the competent board of legal issues and human rights, whose sub-board of human rights reviews the list and organizes a discussion with the candidates. The conversation is usually held in Paris in the premises of the Council of Europe. The candidate is presented to the sub-board in a proportionate short examination of 20 minutes. Before that, the sub-board is already familiar with the candidate's biography, professional papers, as well as political and social activities. The conversation to the candidate is only to get to know the person in full. Ten delegates from the people from different countries sitting on the sub-board are authorized to ask the candidates questions about their work and practice, knowledge of the Convention and human rights as well as many other questions they consider appropriate. The conversation is conducted in the Convention languages, either English or French.

Upon completion of the conversation to the candidates, the subboard announces the result of its findings to the board, and the board may, if deemed appropriate, announce the rank list of the candidates and give preference to any of these.

\footnotetext{
${ }^{10}$ See also Report of the Committee for legal issues and human rights for the Resolution 1366, which additionally elaborates the general qualities that will be assessed at the candidates
} 
Such procedure of the board has a great influence on decision making in the plenary of the Parliamentary assembly, where the board's recommendation is generally adopted. However, the board may propose to the Parliamentary Assembly, the government of the responsible country to return the list of candidates, so that the government will be required to make a new list. This is done when the proposed candidates are not proportionate, i.e. when the board concludes that one of the candidates is so much more powerful that correct selection cannot be done. This is no allowed at all because the procedure would mean that the selection of a judge from the Parliamentary Assembly is transfer to the government of the country member.

However, in such circumstances the contractual country reserves the right to nominate candidates. Therefore, if the country insists on the same list as the one previously rejected, then a blockade occurs, for which the Convention did not provide a solution. Such stagnation occurred to the list of Malta, which was rejected by the Parliamentary Assembly because there were not female candidates. The Maltese Government addressed to the Assembly explaining that the list is a result of a transparent public selection process but that qualified women candidates did not applied at all, so it is inappropriate for the Parliamentary assembly to impose such a rigorous rule without having in consideration the difficulties that small countries face in finding sufficiently qualified candidates in both genders. During the blockade, Malta persuaded the Committee of ministers to seek advisory opinion from the Court in two issues: first, whether, the list that meets the criteria set out in article 21 could be rejected on the based in gender ground, and second, if the relevant resolutions of the Parliamentary assembly in which the request for gender representation on the candidate list was adopted is a breach of the duties of the assembly according to article 22. In the advisory opinion of 12 of February 2008 the Court did not find it necessary to answer the second question and answer only the first one, stating, that although there is not implicit link between the criteria defined in article 21 and insisting to mixed gender list, the policy of gender equality could, in principle, constitute basis for getting list by the Assembly. In realization of such policy, however, there are borders that the Assembly is not allowed to cross. In particular, this should not have effect in making it difficult for the contractual parties to nominate candidates who meet all the requirements of article 21 , especially for countries where the legal profession is small. Thus, the practice of the Parliamentary assembly which does not allow such exceptions was assessed as incompatible to the Convention. The Assembly also made some certain efforts to reform the way countries produce their candidate lists. For example, the recommendation 1429 (1999) invites the countries to publish an open call for applications through specialized print media, consult national parliaments when the list is being defined, as well as to submit a list of candidates in alphabetical order, in order to avoid manifestations of possible preferences. These efforts produced mixed results. Certain number of countries, such as the United Kingdom and Ireland, are inviting candidates publicly. 
In Great Britain, at the last elections, an independent selection board was established, which included a representative from the Commission for equal opportunity, a judge of the Appellate Court of England and Wales, and the Lord-President of the Court in session, although other countries were slow in the implementation of such part of the recommendation, but it seems that the alphabetical schedule is fully respected..$^{11}$

\section{Ineligibility to perform the function and withdrawal}

As stated previously, article 21 paragraph 3 provides that judges shall not be engage in any activity incompatible to their independence, impartiality or the requirements of full-time employment. Occasionally, judges withdrew from examining individual cases due to inevitable conflict of interests, most often when a judge previously had high judicial function in his country had already been involved in a hearing in a case of national level or had been involved as a lawyer. In the early years of the new Court, judges who were formerly members of the Commission had to resign because they had previously reviewed the same case in the Commission. Similarly, judges who were formerly government agents or ambassadors involved, even indirectly, in dealing with cases before the Court, shall not be able to hear cases that have been referred to their governments while they have been in such capacity. Article 28 paragraph 2 defines situations where a judge may not participate in hearing of each

\footnotetext{
11 The Parliamentary assembly shall put them in alphabetical order if the list is not submitted in such shape, but of course the preference of the country shall remain visible. As a result of the Advisory opinion, the Assembly changed the rules in order to allow exceptions regarding the gender term.
}

case, which involves his personal interest or when judges have publicly stated views regarding the case, that are "objectively capable of negatively affect in their impartiality". The mere fact that a judge has written a scientific article on the interpretation of a provision of the Convention and expressed a general view of judicial practice, unrelated to the facts of the review subject, will not usually disqualify him from performing his function. But like any court, difficult questions of assessment can arise here as well. Usually, the judge himself shall only inform the president that he cannot be in session, and article 28 paragraph 1 places the burden of reporting on the judge, who must notify the relevant president if he is prevented from performing his function in a specific case. If there is any doubt in the judge or the president regarding the existence of grounds for ineligibility to proceed, then under article 28 paragraph 4 , the matter is decided by the Judicial council (or, where appropriate, by the Great judicial council) without the presence of the judge concerned, but after he is given the opportunity to express his views on the matter.

\section{Ad hoc and judges in case of mutual interest}

If a judge withdraws from a case, if it is not a case in which he/she is a national judge, then his place would be taken by one of the deputy judges of the Judicial Council or the Great judicial council. If he/she is a national judge then it requires appointment of another judge, as article 28 requires the presence of a national judge. 
In accordance to the arrangement introduced to facilitate the work of the Court and accepted by government agents, the President shall ask the defendant Government to decide whether to appoint another selected judge for the case or shall accept ad hoc. ${ }^{12}$ The Convention itself does not regulate the appointment of ad hoc judges, except in article 27, paragraph 2, providing that the judge selected as representative of the country which is party of the dispute is an ex officio member of the Council and the Great judicial council, in case of his absence or when he is unable to proceed, the country - party of the dispute shall designate a person who will proceed in capacity of a judge. This is elaborated in article 29 of the Rules of Procedure. The defendant government has 30 days to nominate either another selected judge or an ad hoc judge. If it fails to do so within the prescribed time limit it shall be considered to have waived its right to an appointment, article 29 paragraph 1 clarifies that ad hoc judges must possess the qualifications required to in article 21 paragraph 1 of the Convention and must not be ineligible for proceeding in any of the grounds referred to in article 28 of the Rules of Procedure. ${ }^{13}$ This is a matter to be decided by the council or the Great judicial council and article 29 of the Rules of Procedure clarifies that the government shall be considered to have waived its right to appoint if twice appoints persons who do not meet the conditions for performing the function. There is no reference to article 23 paragraph6 here, so there is no requirement for an ad hoc judge to be under the age of 70 . This is a lucky omission as it allows appointment of an ad hoc judge by experienced former judges of the European Court.

\footnotetext{
${ }^{12}$ See the example appointment of judge selected in San Marino to replace the judge selected in Italy. Labota V Italy 2000-IV

${ }^{13}$ They must meet the requirements of availability and presence.
}

Neither the Convention nor the Rules of Procedure leave the possibility of disputing a judge or an ad hoc judge, although it is left the possibility the applicant, the contractual party or third party which is not a party in the dispute to request withdrawal of the president of the Council, stating the reasons for such an objection. Then the president shall have to make a decision, after consultation of the Council. Moreover, as the provisions of the Rules of Procedure do not provide consultation to the applicant before appointment of an ad hoc judge, it is not possible to draw a conclusion on the existence of a veto, so the issue is completely in full discretion of the Council. ${ }^{14}$

Protocol 14 shall amend the rules in respect to the nomination of ad hoc judges. Each contractual party shall have to make a reserve list of ad hoc judges from which, if necessary, the president of the Court can make selection. The Explanatory report of the Protocol explains that this reform is a reply to the criticisms of the current system, particularly expressed in the Parliamentary assembly, due to allowance of the contractual country to select an ad hoc judge after the procedure has already commenced.

\footnotetext{
${ }^{14}$ The question was raised in the fourth Cyprus interstate case against Turkey in 2001 - where both the defendant government and the government-applicant objected to a series of ad hoc judges appointed by others after a judge selected from Turkey withdrew from the case, and the Turkish government filed an objection regarding the selected judge regarding Cyprus. It seems, in any case, the decision, whether national or ad hoc judges are eligible was finally decided by the Great judicial council and in accordance to accordance to article 4 of the Rules of Court. Although is not explicitly established neither in the Convention or the Rules of Court, a third party could object to an ad hoc judge, especially if it is a country exercising the right to intervene.
} 
Correct details of the way this system shall function, in respect to the number of persons on the reserved list and the level of the obligation if selected to proceed, is left to the Court to regulate with the Rules of Procedure.

Finally, when two or more applicants or defendant countries have a common interest in a specific case, for example, when an appeal is filed against more than one contractual countries, it shall be possible for them to nominate a common judge (common interest judge). This was a situation, for example, in the case of Behrami and Saramati vs France, Germany and Norway, which referred to actions of UMNIK in Kosovo, where the three defendant governments agreed to appoint Judge Costa, a judge selected by France currently President of the Court, to be a common interest judge.

\section{Conclusion}

From this paper can be concluded that the adoption of the European Convention of Human Rights, and thus establishing of the European Court of Human Rights, has a key role in history in the efforts of a growing number of countries for adoption an instrument for a wider domination of the inviolability and sovereignty of the fundamental human rights. The fact that the Convention has been signed by a number of states from the European continent, including Russia, this document, which has a formal written form, gains the force of a constitution over the constitutions, while the European Court of Human Rights could be called as court of the courts. Having in consideration the possibility that any individual may file a complaint of any violation of any right guaranteed by the Convention, there is a tendency for approaching of these instruments of governance to a growing number of citizens, regardless their geographical affiliation, within the territory of the petitionary countries. This means aligning of all legal entities to a same starting point in each attempt of exercising their rights, which is in fact the main goal of the Convention. This is essence, this is what guarantees freedom and it is a very definition of a democratic spirit. That means that when a right or freedom guaranteed in the Convention is violated, individuals and even the weakest one can address the court before where they will be equal to the largest countries and governments. The court is at the very center of the human rights protection system, which influences over the democratic legal order of almost all European countries. Its present form is a result of a long-year's process of development and improvement of both the procedure and its organizational set-up. The two protocols (Protocol 11 and 14) are the most important for the reforms carried out. The reforms are inspired by the idea of developing human rights and increasing their efficiency by overcoming biggest problems in functioning of the protection system. The revolutionary of the protocols was consisted in introduction of new Permanent Court (located in Strasbourg), which replaced all existing machinery in order to make it more accessible to individuals, to speed up the court procedure in order greater efficiency in that context. Its structure and organization enable easy access for the citizens of Europe to the court, and their complaints will be treated consistently and thoroughly by court formations, and their violated rights will be protected. 


\section{Reference}

Harris, O'Boyle \& Warbrick, Law on European Convention of Human Rights, page 815-835.

Ananiev, J., Authorized lectures in the subject of Human Rights, Faculty of Law - Kochani, University "Goce Delchev" -Shtip.

Philip Leach, Filing a case before the European Court of Human Rights.

Steiner, H. J., Alston, P. (1996), International Human Rights.

Greer, S., (2009), European Convention on Human Rights, Prosvetno Delo AD Skopje.

Internet:

- Court website - http://www.echr.coe.int

- Convention for the Protection of Human Rights and freedoms amendedhttp://www.echr.coe.int/NR/rdonlyres/28D B92A0-FCBC-40DB-86CB645A8028A019/0/MKD_CONV.pdf 